vessel or more. At operation all patients had the aneurysm resected, and 18 had saphenous vein bypass grafts or other additional procedures. There were two surgical deaths and one death at six months, all in patients with severe disease. Of the 29 survivors after six to 56 months' follow-up, 18 were leading a normal life on no drugs, five were asymptomatic on treatment, and three had dyspnoea. Two patients had persistant angina; in one of these the graft had blocked.

These results show how good the symptomatic benefit may be in selected patients-though many of the patients had additional procedures. Ultimate prognosis may also be affected: in a large series from Cleveland ${ }^{5}$ the four-year survival in patients treated by operation was $76 \%$ compared with a five-year survival of less than $20 \%$ in those who were treated medically. Death was usually due to reinfarction or intractable failure, and hardly ever to rupture of the aneurysm. Clearly the two groups were not comparable, since the surgical patients were highly selected.

When a patient develops persistent failure or angina, or both, after an infarct (especially if it is his first) some mechanical complication should be suspected. If ventricular septal defect and mitral regurgitation have been excluded, then an aneurysm should be sought. In well-chosen cases surgical treatment provides good symptomatic relief and may well prolong life.

${ }^{1}$ Edwards, T E, An Atlas of Acquired Diseases of the Heart and Great Vessels, vol 2, p 615. Philadelphia, W B Saunders, 1961.

2 Dubnow, M H, Burchell, H B, and Titus, J L, American Heart fournal, $1965,70,753$.

3 Schlichter, J, Hellerstein, H K, and Katz, L N, Medicine, 1954, 33, 43.

4 Donaldson, R M, et al, British Heart fournal, 1976, 38, 1223.

${ }^{5}$ Loop, F D, et al, Annals of Surgery, 1973, 178, 399.

\section{Topical corticosteroids and relapses of psoriasis}

Many patients have psoriasis so mild that they hardly need to seek medical advice; in others it may ruin and even threaten their lives. Sometimes the disease runs an unfluctuating course over many years; more usually there are definite fluctuations from time to time, often for no apparent reason and unrelated to factors such as infections, trauma, season, or emotions. We know little about the long-term history, with or without treatment, in the mass of psoriatics, partly because most series (with a few exceptions ${ }^{1}$ ) are based on hospital statistics. The duration and completeness of remissions induced by treatment are surely just as important as how quickly they are achieved.

For the relatively few really bad cases of psoriasis unresponsive to conventional inpatient treatment potent drugs such as methotrexate, hydroxyurea, and other antimitotic agents are both justified and effective. ${ }^{2}{ }^{3}$ There is virtually no place for systemic corticosteroids. The recently introduced PUVA therapy ${ }^{4}$ long-wave ultraviolet light-is gaining popularity, but until the long-term side effects have been assessed it should be reserved for the very severe cases, and in any case such treatment is not generally available in Britain.

Patients with ordinary psoriasis are usually treated with topical applications of tar, dithranol, or corticosteroids, perhaps combined with ultraviolet light, either as outpatients or more effectively as inpatients. ${ }^{2} 6$ Healing rates with different regimens have been compared often and in detail, and it seems that topical steroids act more quickly, are cleaner and therefore more popular, but often fail to achieve complete clearance. They tend to fail in the more difficult patients with widespread or inflamed psoriasis. Persistence with steroid treatment in such cases has almost certainly been responsible for the very definite increase in the past 20 years of the more unpleasant types such as pustular psoriasis. ${ }^{7}$ The relapse rate after various topical treatments is far less well known. Over ten years ago patients given fluocinolone under occlusion were found to relapse more quickly than those given conventional tar treatment, ${ }^{8}$ so it seemed reasonable next to try a combination of tar or dithranol with a topical steroid, which might allow the best of both worlds. A recent retrospective comparison $^{9}$ of psoriatics treated as inpatients with topical betamethasone valerate under polyethylene occlusion combined with dithranol and another group treated with dithranol alone showed that the rate of clearance in the two groups was comparable, the group given dithranol alone taking marginally longer. Nevertheless, the relapse rate was strikingly different: the mean relapse time was five weeks in those given steroids plus dithranol and 28 weeks in those given dithranol alone. Such studies are hard to organise, but further long-term trials, preferably prospective, are needed.

Should these findings be extrapolated to other topical steroids or to steroids without polyethylene occlusion ? Weak nonfluorinated steroids give disappointing results in psoriasis. Very strong steroids such as clobetasol propionate achieve immediate clearance of psoriasis even without polyethylene, but it might be thought that they would have even greater potential for damage to the skin, to the pituitary-adrenal axis, and to the long-term natural history of the disease. Nevertheless, in a small series of patients Marriott and Munro ${ }^{10}$ found that the relapse rate after clobetasol was slower than after dithranol.

For the moment the conclusion must be that the use of topical steroids is no panacea or even the best long-term management for most patients with psoriasis. They are useful in localised psoriasis, but not indefinitely, and steroids must not be used in increasing quantities in the face of clinical deterioration. In long-term treatment the dose of strong steroids should be kept below $25 \mathrm{~g}$ weekly and the clinician should watch for early signs of skin atrophy. In more extensive cases of psoriasis the temptation to use topical steroids for long periods must be resisted. Some of these patients may improve a lot when given a strong steroid for up to six weeks, and then do not necessarily relapse when the steroid is stopped (which should be done gradually, replacing with a weaker steroid or with the same one diluted). If they do relapse an alternative treatment must be sought. Topical use of dithranol or tar is still worth while, and both become much more powerful remedies when used in inpatients. There is still truth in the dictum that the more powerful drugs should not be used until conventional inpatient treatment has been proved wanting.

${ }^{1}$ Lomholt, G, Psoriasis. Copenhagen, Gad, 1963.

${ }^{2}$ Dahl, M G C, British Medical fournal, 1971, 3, 234.

${ }^{3}$ Farber, E M, Pearlman, D, and Abel, E A, Archives of Dermatology, 1976, $112,1679$.

4 Wolf, K, et al, Archives of Dermatology, 1976, 112, 943.

${ }^{5}$ British Medical fournal, 1975, 1, 474.

6 Baker, H, Dermatologica, Basel, 1975, 150, 136.

${ }^{7}$ Baker, H, British fournal of Dermatology, 1976, 94, suppl 12, 83.

${ }^{8}$ Knudsen, E A, Acta Dermatovenereologica, 1965, 45, 50.

${ }^{9}$ Seville, R H, British fournal of Dermatology, 1976, 95, 643.

${ }_{10}$ Marriott, P J, and Munro, D D, British fournal of Dermatology, 1976, 94, suppl 12, 101 